\title{
GEOGRAPHICAL PATTERNS OF CULTURAL VALUES, ENTREPRENEURSHIP AND ECONOMIC DEVELOPMENT
}

DOI: http://dx.doi.org/10.18509/GBP.2015.50

\author{
Associate Professor Dr. Riste Temjanovski \\ Assistant Professor Dr. Tamara Jovanov Marjanova \\ Goce Delcev" University - Faculty of Economics, Stip, Republic of Macedonia
}

\begin{abstract}
Globalization and information technologies are new realities that have brought profound changes in lifestyles worldwide. This is reshaping the overall pattern of life custom, cultural production, consumption and trade in a world increasingly filled with changes and economic diversity. In an age of globalization, often ask questions and discussions concerning about successes and vitalities of nations. Globalization and technological revolutions race ahead and transform the world, and how to traces the real business to success.

There are thousands of good examples where any nations have shown entrepreneurial talents and have succeeded. It is culture that principally explains, in many cases, or geographical pattern where some countries are developing more rapidly and more successfully than others. How to explain economic success of this nation's miracles or simple the secret is creative entrepreneurships?

This paper explores the complex interactions between the geographic pattern from one side and cultural, technological and social aspects of entrepreneurship from other side which generates the dynamic processes of the world economy. In this era of transformation, creativity and knowledge entrepreneurship are powerful tools of fostering economic progress and development.
\end{abstract}

KEYWORDS: geographical pattern, culture, entrepreneurship, economic activity and development,

\section{INTRODUCTION}

The idea and one of the central questions in this paper is why disparities in success and development across countries are large and persistent. Despite decades of research, this question continues to motivate the science and individuals, how to find the secret algorithm among the economic success countries.

The question that culture is a central ingredient of economic development goes back to at least Max Weber who, in his classical work "The Protestant Ethic and the Spirit of Capitalism,". This brilliant masterpiece may serve as the best available foil for a first attempt to identify the constructive elements of the culture of modern economic research. Weber was right after all in suggesting that social attitudes and values have the decisive say on what economies will succeed and which will fail and he saw culture as the driving force behind differences in economic development.

In an even more recent book, The Wealth and Poverty of Nations, David Landes concludes that the success of national economies is driven by cultural factors more than anything else. Thrift, hard work, tenacity, honesty and tolerance are the cultural factors that make all the difference, he suggests. In addition to culture, there was geography. It is 
always logically tempting to rely on geography because by and large geography is truly exogenous. Culture, technology, trade, institutions, and government, all are determined by each other in a logically overdetermined system. But geography, climate, soil fertility, and accessibility are all largely given, and so they determine economic growth but are not determined by it.

Although many others scientists have argued that culture played a fundamental role in explaining the wealth of nations and the literature on the economic effects of culture is growing fast, there has so far been little systematic work examining theoretically and empirically the effect of culture on long-run growth and development.

Culture, in all its multiple forms, is essential to address these global challenges, through its role and economic growth, in human development, as a storehouse of environmental knowledge, and as a symbolic force to bring stability and meaning to communities everywhere. Principles of inclusiveness and global ethics enable even the most marginalized individuals and groups to participate in development processes and benefit from them. Culture provides solutions that respond to local specificities, as a driver of development in its own right as well as a desirable outcome of development efforts. [11] Culture can influence economic activity in diverse ways: Culture is known to influence attitudes towards work and consumption. Culture has an influence on the organization of economic activity and the shaping and effectiveness of institutions, and culture also has an impact on social networks and confidence building within social groups. [2] Some of the activities related to culture generate, additionally, an analogous economic impact to the one produced by other sectors of the economy.

In one word, culture is, besides an indispensable element for social cohesion and the reconstruction of an identity, an economic sector equally or even more important than any other productive sector of society. The economic transactions that take place in the deepest heart of culture generate positive economic effects such as learning and knowledge. That is, the cultural sector contributes to development from the social and identity sectors, such as from the economic ones.

In this paper we try to examine how cultural values moderate the relationship with economic activities in different societies. More specially, our analyze suggests that depending on the economic development national culture may affect different types of entrepreneurial activities, or innovation challenges in different ways. We argue that in different society's cultural variables impact for the differences in the quantity and quality of entrepreneurial activities.

\section{RELATIONSHIP BETWEEN CULTURE AND CREATIVITY}

Culture is total learned way of life of a society. Culture can be defined as the body of beliefs, customs, traditions, social forms, and material traits constituting a distinct social tradition of a group of people. Cultural practices include religion, and attitudes towards family size as well as language, which is the transmission of idea through symbols, signs, and dialects.[9]

Culture is the human endeavor that par excellence produces feelings and imaginaries in society. It also reinforces the feeling of identity and citizenship. Culture is precisely the medium through which individuals express their ability to fulfil themselves and is therefore an integral part of development. [3]

Creativity. A word of multiple definitions, which intuitively refers not only to the ability of creating the new, but also to the ability of reinventing, diluting traditional paradigms, 
uniting apparently disconnected points; and that would lead us to finding solutions for new and old problems. In economic terms, creativity is a renewable fuel, and its stock increases with use. Furthermore, "competition" among creative agents attracts and encourages the action of new producers, instead of saturating the market.

Creativity is the mental and social process used to generate ideas, concepts and associations that lead to the exploitation of new ideas. Or to put it simply: innovation. Through the creative process, employees are tasked with exploring the profitable outcome of an existing or potential endeavor, which typically involves generating and applying alternative options to a company's products, services and procedures through the use of conscious or unconscious insight. This creative insight is the direct result of the diversity of the team - specifically, individuals who possess different attributes and perspectives. Culture and creative economy have always walked pari passu since the interpretation of both concepts reflects an era and its values. Cultural and creative goods and services are rooted in our lives and we consume them without necessarily having the market intermediation. In this context, managers speak of developing the "right kind of culture," a "culture of quality" or a "culture of customer service," suggesting that culture has to do with certain values that managers are trying to inculcate in their organizations.[12] The core issue is: the sustainability of cultural production depends on the aptitude of talents (which implies that cultural producers can live off their own production or have idle time to devote themselves to it as a hobby); on the circulation of this production or tradition (thus guaranteeing the renewal of cultural diversity); and on the guaranteed access to this production (especially for young people) in a play of forces of mass culture, which is instigated by globalization. [6]

\section{REGIONAL CULTURES DIVERSITY AND IMPACT ON ECONOMIC ACTIVITY}

Cultural values and norms influence attitudes and patterns of behavior and in this way have an impact on economic activities. When empirically verifying these approaches, it proves problematic that culture cannot be measured directly. Culture acts as a kind of background variable that manifests itself in attitudes and patterns of behavior. Apart from cultural background, a number of other individual-related influences determine attitudes and patterns of behavior, too. Furthermore, people belong to different social groups. That is why regional cultural features overlap with group-specific cultural features. Persons with the different regional cultural background manifest different attitudes and patterns of behavior.

\section{Swiss case}

To mention some features of the culture and thinking of the Swiss nation culture. Swiss political system is a system through which different people with different languages and religions fulfill their specific form of democracy. Characteristic of this country when making policy decisions, is that "never no rush".

In the process of political decision-making is widely used instruments of direct democracy, in particular the referendum. As a rule, every law enacted by the assembly Swiss go to referendum. Swiss people is a very specific in many things.

- Rejected a proposal to introduce a 40-hour work week, why you think in the interest of the community to work longer 
- Do not accept the proposal - the retirement age be reduced on the grounds that it would be too expensive for the state,

- Swiss voted in favor of raising the price of bread, when the government explained the necessity of such a move (because price hike of wheat on world markets), etc.

- Rejected the idea of limiting the amount of salary managers (by a majority of $66 \%$ of voters) up to 12 times the minimum wage and therefore agree that managers deserve to have astronomical amounts of income, if it makes them happy employees and companies (known as 1:12).

Using those specific characteristics, many last years, Switzerland retains long time its 1st place position in Global Competitiveness Index as a result of its continuing strong performance across the board. The country's most notable strengths are related to innovation and labor market efficiency, where it tops the GCI rankings, as well as the sophistication of its business sector, which is ranked 2nd. Switzerland's scientific research institutions are among the world's best, and the strong collaboration between its academic and business sectors, combined with high company spending on $R \& D$, ensures that much of this research is translated into marketable products and processes reinforced by strong intellectual property protection. While Switzerland demonstrates many competitive strengths, maintaining its innovative capacity will require. Boosting university enrollment, which continues to lag behind that of many other high-innovation countries, although this has been increasing in recent years.

\section{Germany's miracle}

After World War II, Germany was mentioned as "economic miracle". For this saying Ludwig Erhard, Federal Minister of Economics from 1949-1963, rejecting this name, says: "There are no miracles, all this is simply the result of sincere effort on the part of the German nation of which have been given the opportunity and freedom to best done by human initiative, culture, freedom and power of German nation." Germany's economic policy decisions after 1948, based on ordo-liberal creed, played an important role in freeing the growth forces after the misallocation of resources through war and post-war administration.

Today, the main economic policy of Germany is based on the development of social and responsible market economy. The economic system rejected the laissez-faire doctrine and the mainly government intervene in business decisions. State plays a key regulatory role in a market economy. It created the basic conditions for market processes. But in that context million households and businesses freely decide what to spend and produce. The German economic growth performance after 1948 had many "fathers", not only Erhard, the "father of the economic miracle", like every successful model. But, while macroeconomic explanations are important to understand the growth dynamics after the war, they cannot explain the superior performance as well compared to European neighbouring market economies or to centrally-planned economies with a similar war experience. This is particularly true for the first ten years of the Social Market Economy, when the economic dynamic was markedly different. However, if Germany indeed had a superior performance, does that mean that growth is dependent on an ordo-liberal model? Economic policy and economic history are not simply determined by mechanic historical „forces“, but also the result of personalities, creativity and alertness, or, as Ludwig von Mises put it, ,homo agens“.[7] 


\section{Israel entrepreneurial challenge}

The next question is how to explain Israel's high-tech success and analyze the major factors that contribute to Israel's economic growth. How is it that Israel-a country of 7.1 million people, only sixty years old, surrounded by unfriendly neighbors, in a constant state of war since its founding, with no natural resources-produces more start-up companies than large, peaceful, and stable nations like Japan, China, India, Korea, Canada, and the all of Europe, and that after the United States, Israel has more companies listed on the NASDAQ than any other country in the world.

The innovation is the reason for Israel's economic success. "Making innovation happen is a collaborative process on many levels, from the team, to the company, to the country, to the world.

The importance of corporate culture is a remarkable addition to corporate priorities. Yet, while forward-looking companies recognise the true potential of corporate culture, many in the financial services sector still see it as only one tool that will protect them from potential outside scrutiny. Too few understand the direct link that exists between culture and financial success. Understanding the role, value and benefits of corporate culture will enable financial services companies to engage with their employees in ways that are more profound - and in the end, may go a long way to building that culture of trust which will be invaluable when the industry hits those rough patches and times of potential crisis. In fact, Israel's built a startup culture that rivals Silicon Valley:[8]

- Israel has a highly educated entrepreneurial community (40\% with Masters/PhD vs $42 \%$ in Silicon Valley).

- Tel Aviv-based startups actually employ as many people per stage as their Silicon Valley counterparts do.

- Funding is strong ( $\$ 600 \mathrm{M}$ in Q3 2013, back to pre-bubble highs) and working hours long.

Culture is vitally important because in an era of largely commoditised technology and short-term differentiation, it is the way organisations chose to operate that is the only real source of competitive differentiation. This goes to the heart of culture and values. Therefore the measurement of this goes far beyond some kind of cultural health diagnostic. Cultural attributes cannot be reported on usefully on an annualised basis, but they are significant assets that an organisation can draw upon to help shape a successful future. And perhaps more significantly, help to course correct in the case of a crisis or scandal.

\section{The others cases}

Certainly, in the world we have many more examples where culture is one of the driving forces of economic and social prosperity of the nation. Most of this achievement is attributable to seemingly miraculous growth in just eight high performing Asian economies - Japan; the "four tigers": Hong Kong, the Republic of Korea, Singapore, and Taiwan; and the three newly industrializing economies (NIEs) of South-east Asia Indonesia, Malaysia and Thailand. The East Asian economies provide a range of policy framework - extending from Hong Kong's nearly complete laissez faire to the highly selective policy regimes of Japan and Korea. The coexistence of activist public policies and rapid growth in some of the East Asian economies - especially Japan, Korea, Singapore and Taiwan - has raised complex and controversial question concerning the relationship between culture, government, the private sector and the market. [4] 


\section{GLOBALIZATION AND THE IMPACTS OF CULTURAL CHANGES TO ECONOMIC DEVELOPMENT}

Globalization, Internet and information technologies give a new dimension to the market and operation. All three forces boost the innovation change and reshape the economic patterns and consequently strategy to world success.

Innovation, motivation and culture go hand-in-hand to present global world. Informational issues are central to entrepreneurship theory. Opportunity identification, investigation, and exploitation can be seen as an information collection process, with entrepreneur's optimal strategy being closely related to this information costs, and his beliefs.[1] For instance, some entrepreneurs already in the relevant industry might be able to cheaply trial a new idea, while for others trailing the same idea could be much more expensive.

Figure 1 Global Entrepreneurship Monitor and survey of entrepreneurial activity

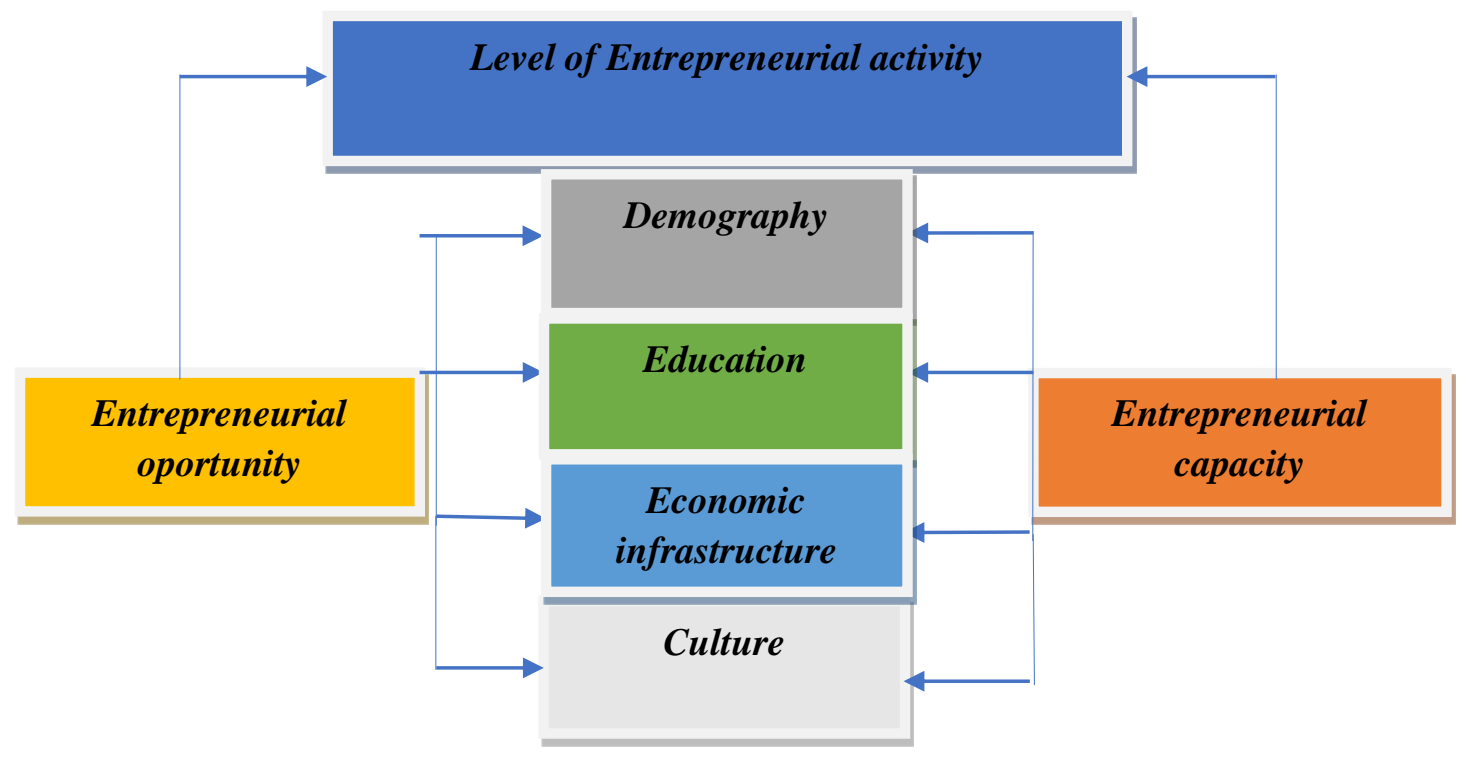

Source: David Deakins \& Mark Freel, “Entrepreneurship and small firms”, $4^{\text {th }}$ Edition, McGraw-Hill International, 2005, p.21

There is a close link between the level of entrepreneurial activity in an economy and the level of economic growth (shown in Figure 1). Economies will vary according to their level of entrepreneurial activity that would directly affect the growth of GNP (gross national product). Especially significant review of correlation between entrepreneurial activity and development can summarized of the Global Entrepreneurship Monitor (GEM). GEM proposes that additional factors influence the level of entrepreneurial activity can be represented by the model. GEM model consists of factors on the demand side and the supply side that can be measured. Demand side is represented by entrepreneurial opportunities and the supply side with an entrepreneurial capacity.

The creative culture participates in the economic vitality and competency in five ways (shown in Figure 2).:

1) As part of the nationality mark, tradition and religion (national and traditional habits); 
2) Transforming the new process of Technology and innovation (innovation and knowledge and the possibility of new products and services based on digital technology);

3) Having an impact on Education and Science (culture creation and educations);

4) Implemented state regulation (stimulates measure for Entrepreneurship)

5) Depending of Individuality (personal and self-perception challenges);

Establishing a creative environment takes more than just turning the employees loose and giving them free reign in the hope they'll hit on something valuable. As with any other system, the process of creativity requires the proper framework to operate effectively, which also enables management to evaluate the profitability of the results.

Figure 2 Contribution of variety of creative culture to social and economic vitality

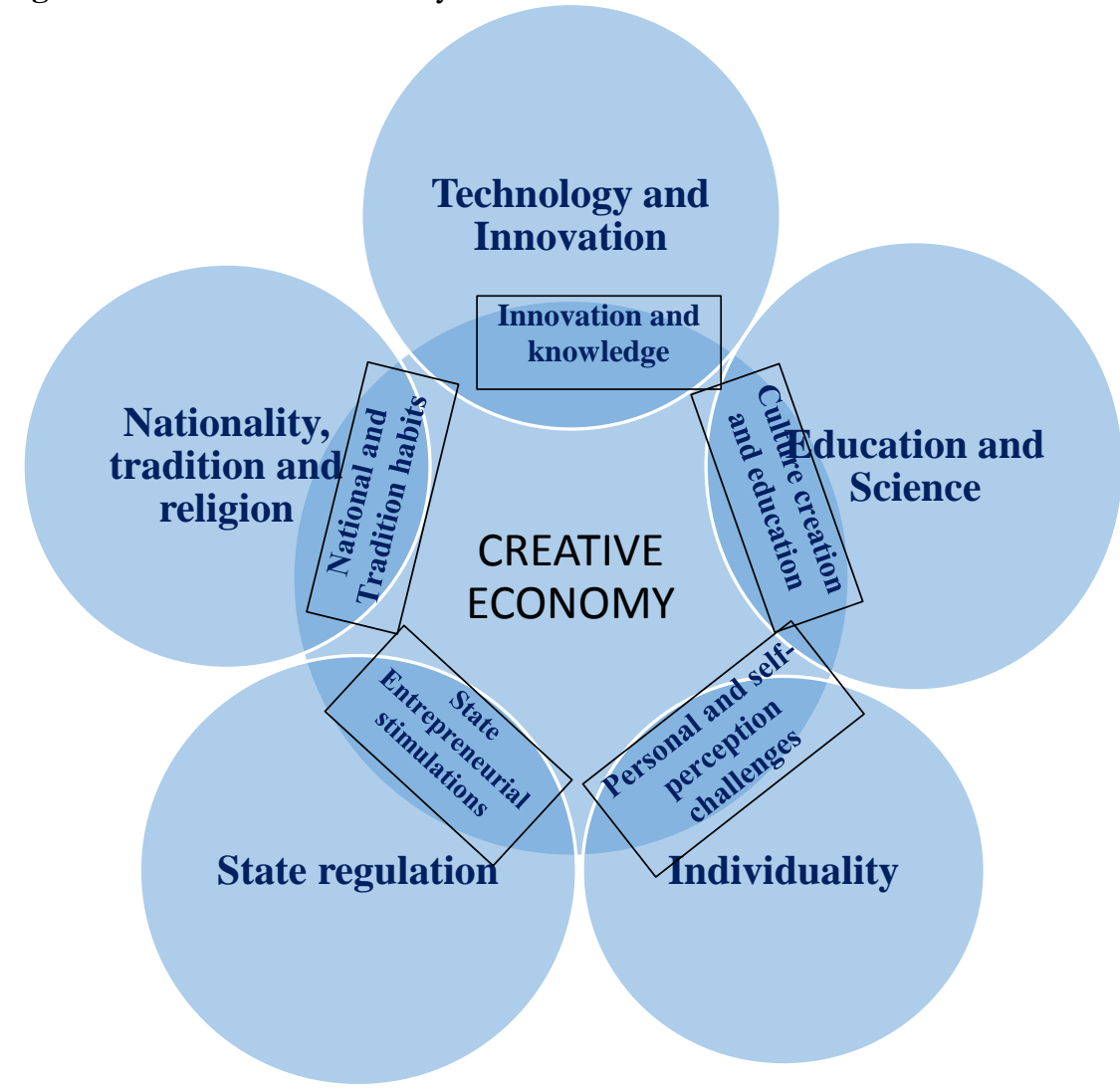

Indeed central question now arises is how injected the cultural tissues of the individua, what economic theory and practice which take as a universal value of any society. Individual initiative, risk-taking and responsibility, contributing to the creation of ventures for their own benefit and for the benefit of the company, improve its stability and performance, also efficiency and stability of the economy and society. These features provide a broader and universal significance of cultural signs that are moving towards introducing innovations, creating ideas and providing venture capital to drive and implement ideas.[10]

\section{SUMMARY}

Nowadays, the process of globalization, new technological and cultural practices give a new dimension to the market and operation around the world. All three forces reshape the perception of success in world economy. The creative economy comprises 
multidisciplinary approach dealing with the interface between economics, culture, and technology, designed of products and services with creative content, cultural value, and market objectives, which result from a gradual change business success.

Economists must follow the "pulsing" of market needs, since each economy is influenced by trends or forces that form the global economy. Even if the market of a company is limited to a local geographical area, it may face competitors who are registered out of state and local trading. Individual economists with entrepreneurial specialization cannot isolate themselves from the globalization of the economy. Each business will trade in a global economy, which is an acceptance of the strategies that allow economists to optimize opportunities. These strategies will depend on the available resources, key staff, the type of product and the nature of technology. And indeed the central issue today is made, is injecting the best cultural and spirit values into the cells of the individuals, what entrepreneurship theory and practice which has taken as a universal value of each society.

\section{REFERENCES}

[1] Casson M., [et all.]: The Oxford handbook of entrepreneurship. Oxford: Oxford University Press, 2006. 106 p.

[2] Fukuyama, F. (2001): "Culture and Economic Development: Cultural Concerns", International Encyclopedia of the Social and Behavioral Sciences, Elsevier, Amsterdam et al., 2001, pp. 31303134.

[3] Inter-American Council for Integral Development: Culture as an Engine for Economic Growth, Employment and Development. II Inter-American Meeting of Ministers and Highest Appropriate Authorities of Culture. p.1. (www.oas.org/udse/.../temalestudio.doc 30.10.2014)

[4] Page John: The East Asian Miracle: four lessons for development policy. NBER Macroeconomic Annual 1994, vol.9. p.219-282.

[5] Peter F. Drucker, Innovation and Entrepreneurship, Publisher: Harper Paperbacks, 2006, стр. 49

[6] Reis Fonesca A.: Creative economy: as a development strategy: a view of developing countries. Sao Paulo: Itau Cultural, 2008. p. 33.

[7] Seliger B. Theories of economic miracles. Discourses in Social Market Economy. Diskurs 2010-1. p.7-14.

[8] Senor D., Singer S.: Start-up Nation: The Story of Isael's Economic Miracle. http://www.forbes.com/sites/zackmiller/2013/12/17/from-start-up-nation-to-scale-up-nation-israelcirca-2014/

[9] Stutz P.F., Ware B. The World economy: resources, location, trade, and development. Pearcon. Prentice Hall. New Jersey, 2005.p14.

[10] Temjanovski R., Svrtinov G.V., Trajkovska Gjorgieva O.(2014): Moral Values, information and science. International Journal: Scientific \& Applicative Papers. Vol.4. Skopje: Institute of knowledge management.p.[119-123]

[11] UNESCO: The Power of culture for development. p.4 (http://unesdoc.unesco.org/images/0018/001893/189382e.pdf 30.10.2014)

[12] Schein H.E. Organization Culture and lidership,Jossey Bass, Business \& Management Series. San Francisko. 2004. p.7 